\title{
3-D supramolecular architectures in the three new complexes constructed from mixed ligands: Syntheses, crystal structures, spectroscopic properties, XRPD and thermal study
}

\author{
Guo-Ping Yang ${ }^{\mathrm{a}}$, Yao-Yu Wang ${ }^{\mathrm{a}, *}$, Hong Wang ${ }^{\mathrm{a}}$, Cui-Juan Wang ${ }^{\mathrm{a}}$, \\ Gui-Lin Wen ${ }^{a}$, Qi-Zhen Shi ${ }^{a}$, Shie-Ming Peng ${ }^{\mathrm{b}}$ \\ ${ }^{a}$ Key Laboratory of Synthetic and Natural Functional Molecule Chemistry of Ministry of Education, \\ Shaanxi Key Laboratory of Physico-Inorganic Chemistry, Department of Chemistry, Northwest University, Xi'an 710069, PR China \\ ${ }^{\mathrm{b}}$ Department of Chemistry, National Taiwan University, Taipei, Taiwan
}

Received 26 September 2007; received in revised form 20 December 2007; accepted 21 December 2007

Available online 11 January 2008

\begin{abstract}
Three new coordination polymers $\left[\mathrm{Cu}_{2}\left(\right.\right.$ bptc)$\left.(\text { bpdap })_{2}\right] \cdot 4 \mathrm{H}_{2} \mathrm{O}(\mathbf{1}),\left\{\mathrm{Zn}_{2}(\text { bptc })(\text { bpe })\left(\mathrm{H}_{2} \mathrm{O}\right)_{6}\right\}_{n}(\mathbf{2})$ and $\left\{\mathrm{Co}_{2}(\mathrm{bptc})(\mathrm{bpe})\left(\mathrm{H}_{2} \mathrm{O}\right)_{8}\right\}_{n}(\mathbf{3})$ $\left[\mathrm{H}_{4}\right.$ bptc $=3,3^{\prime}, 4,4^{\prime}$-biphenyltetracarboxylate acid, bpdap $=N, N^{\prime}$-bis(2-pyridyl)-2,6-diaminopyridine, bpe $=$ trans-1,2-bis $(4$-pyridyl)ethene] have been hydrothermally synthesized in different $\mathrm{pH}$ values and structurally characterized by single-crystal X-ray diffraction. The non-covalent interactions of hydrogen bond extend complexes 1, 2 and $\mathbf{3}$ into supramolecular architectures, where $\mathbf{1}$ exhibits a 3 D framework with 1-D open channels where the guest water molecules are located. Importantly, two kinds of chiral helical H-bonded chains appear in 1, and some types of H-bonded patterns exist in 1, $\mathbf{2}$ and $\mathbf{3}$. It is more remarkable that the building block bptc anion adopts versatile coordination modes in these complexes. The elemental analysis, IR spectra, XRPD and TG analysis are discussed for $\mathbf{1}$, $\mathbf{2}$ and $\mathbf{3}$. In addition, the fluorescence is also studied for $\mathbf{2}$ here.

(c) 2008 Elsevier B.V. All rights reserved.
\end{abstract}

Keywords: Copper; Zinc; Cobalt; 3,3',4,4'-Biphenyltetracarboxylate acid; Supramolecular network; H-bonded helices

\section{Introduction}

The design and synthesis of supramolecular coordination polymeric networks, especially those constructed by hydrogen bonding and $\pi \cdots \pi$ stacking interactions have been a field of rapid growth due to their intriguing variety of topologies and structural diversities, such as helices $[1,2]$ and interpenetrating nets [3], and because of their special physical properties and potential application in functional materials [4]. The coordination chemistry of aromatic polycarboxylate transition metal complexes has received considerable attention owing to the variety of bridging abilities of polycarboxylate in the formation of porous frameworks in the last decades [2a,5]. Our group had con-

\footnotetext{
${ }^{*}$ Corresponding author. Tel./fax: +86 2988303798.

E-mail address: wyaoyu@nwu.edu.cn (Y.-Y. Wang).
}

structed several new architectures when utilizing multicarboxylate ligands $[3 \mathrm{c}, 5 \mathrm{~g}]$, which have diverse coordination modes and are good candidates for H-bonded acceptors and donors that serve as an effective building block for the formation of molecular solids. As a continuing work, we choose another polycarboxylate ligand, 3,3',4,4'-biphenyltetracarboxylate acid $\left(\mathrm{H}_{4}\right.$ bptc, Scheme $\mathrm{Sla}$, see Supporting Information), which possesses several interesting characteristics: (a) it has four carboxylic groups which may be completely or only partially deprotonated to generate $\mathrm{H}_{3} \mathrm{bptc}^{-}, \mathrm{H}_{2} \mathrm{bptc}^{2-}$, $\mathrm{Hbptc}^{3-}$ or bptc ${ }^{4-}$ anionic according to different $\mathrm{pH}$ conditions (Scheme S2, see Supporting Information), inducing rich coordination modes and allowing interesting structures with higher dimensions [6]; (b) it can act not only as $\mathrm{H}$-bonded acceptor but also as $\mathrm{H}$ bonded donor, depending upon the numbers of deprotonated carboxylic groups and whether interacting with the 
metal ions or not; (c) some of the carboxylic groups may not lie in the phenyl ring plane upon complexation to metal ions owing to steric hindrance, thus, it can connect metal ions in different directions. Hence, $\mathrm{H}_{4}$ bptc ligand is undoubtedly a good choice for the construction of polymeric structures.

Although some structural reports on transition metal coordination complexes containing $\mathrm{H}_{4}$ bptc have been reported in the literatures and by us recently $[3 b, 6]$, the studies on the structures of mixed-ligand complexes in this family are still limited. So recently we have engaged in the research of this kind of metal-organic polymers and we also notice that the introduction of N-containing auxiliary ligands, such as $N, N^{\prime}$-bis(2-pyridyl)-2,6-diaminopyridine (bpdap, Scheme S1b, see Supporting Information), trans1,2-bis(4-pyridyl)ethene (bpe) etc., into the $\{\mathrm{M}$ $\operatorname{bptc}\}(M=$ transition metal) system may lead to new structural changes and form new frameworks. Herein, we report the hydrothermal syntheses and structural characterizations of three new coordination polymers, namely, $\left[\mathrm{Cu}_{2}\left(\right.\right.$ bptc) $\left.(\text { bpdap })_{2}\right] \cdot 4 \mathrm{H}_{2} \mathrm{O} \quad(\mathbf{1}), \quad\left\{\mathrm{Zn}_{2}(\text { bptc })(\text { bpe })\left(\mathrm{H}_{2} \mathrm{O}\right)_{6}\right\}_{n}$ (2) and $\left\{\mathrm{Co}_{2}(\mathrm{bptc})(\mathrm{bpe})\left(\mathrm{H}_{2} \mathrm{O}\right)_{8}\right\}_{n}$ (3). The results show that bptc anion adopts diverse coordination modes in the three complexes (Scheme S3, see Supporting Information). On the other hand, importantly, there are two kinds of chiral helical chains directed by H-bonded interaction and 1-D open channels containing free water molecules in complex 1; and some types of $\mathrm{H}$-bonded patterns also exist in the three complexes. Additionally, complex $\mathbf{2}$ shows excellently luminescent.

\section{Experimental}

\subsection{Materials and physical measurements}

All the reagents and solvents were commercially available and used as received without further purification. And $\mathrm{H}_{4}$ bptc ligand was obtained by hydrolyzing 4,4'-biphthalic anhydride that is bought from $A$ lfa $A$ esar, the bpdap was synthesized according to the reported method [7]. The Infrared spectra on $\mathrm{KBr}$ pellets were recorded on a Nicolet 170SX FT-IR spectrophotometer in the range of $4000-400 \mathrm{~cm}^{-1}$. Elemental analysis was conducted with a Perkin-Elmer model 240C instrument. Fluorescence experiments used a HITACHI F-4500 Fluorescence Spectrophotometer. Thermal analysis was performed on a NETZSCH STA 449C microanalyzer in a nitrogen atmosphere at a heating rate of $10{ }^{\circ} \mathrm{C} \mathrm{min}{ }^{-1}$. The XRPD pattern was recorded with a Pigaku $\mathrm{D} / \mathrm{Max}$ 3III diffractometer.

\subsection{Syntheses of complexes}

\subsection{1. $\left.\left[\mathrm{Cu}_{2} \text { (bptc) (bpdap) }\right)_{2}\right] \cdot 4 \mathrm{H}_{2} \mathrm{O}(\mathrm{I})$}

A mixture of $\mathrm{Cu}\left(\mathrm{NO}_{3}\right)_{2} \cdot 8 \mathrm{H}_{2} \mathrm{O}$ (166 mg, $0.5 \mathrm{mmol}$ ), $\mathrm{H}_{4}$ bptc $(83 \mathrm{mg}, 0.25 \mathrm{mmol})$, bpdap $(132 \mathrm{mg}, 0.5 \mathrm{mmol})$ and water $(15 \mathrm{~mL})$ was adjusted to $\mathrm{pH} 6$ with $1 \mathrm{M} \mathrm{NaOH}$ solution and then heated at $145^{\circ} \mathrm{C}$ for 4 days in a sealed
$25 \mathrm{~mL}$ Teflon-lined stainless steel vessel under autogenous pressure. Slow cooling of the reaction mixture to room temperature gave blue block crystals. Yield: $51 \%$. Anal. Calc. for $\mathrm{C}_{46} \mathrm{H}_{36} \mathrm{Cu}_{2} \mathrm{~N}_{10} \mathrm{O}_{12}$ (1047.93): C, 52.72; H, 3.46; N, 13.37. Found C, 52.39; H, 3.38; N, 13.25\%. IR data $\left(\mathrm{KBr}, \mathrm{cm}^{-1}\right): 3408 \mathrm{~s}, 3071 \mathrm{~m}, 2985 \mathrm{~m}, 1665 \mathrm{~s}, 1582 \mathrm{~s}, 1545 \mathrm{~m}$, $1489 \mathrm{~m}, 1453 \mathrm{~s}, 1398 \mathrm{~s}, 1248 \mathrm{~m}, 1213 \mathrm{~m}, 1177 \mathrm{w}, 1158 \mathrm{w}$, $834 \mathrm{w}, 805 \mathrm{~m}, 777 \mathrm{~s}, 711 \mathrm{~m}, 665 \mathrm{w}, 414 \mathrm{w}$.

\subsection{2. $\left\{\mathrm{Zn}_{2}\left(\text { bptc) }(\text { bpe })\left(\mathrm{H}_{2} \mathrm{O}\right)_{6}\right\}_{n}(2)\right.$}

A mixture of $\mathrm{Zn}(\mathrm{OAc})_{2} \cdot 2 \mathrm{H}_{2} \mathrm{O}(110 \mathrm{mg}, 0.5 \mathrm{mmol})$, $\mathrm{H}_{4}$ bptc $(83 \mathrm{mg}, 0.25 \mathrm{mmol})$, bpe $(46 \mathrm{mg}, 0.25 \mathrm{mmol})$ and water $(15 \mathrm{~mL})$ was adjusted to $\mathrm{pH} 7$ with $1 \mathrm{M} \mathrm{NaOH}$ solution and then heated at $145^{\circ} \mathrm{C}$ for 4 days in a sealed $25 \mathrm{~mL}$ Teflon-lined stainless steel vessel under autogenous pressure. Slow cooling of the reaction mixture to room temperature gave colorless crystals. Yield: 58\%. Anal. Calc. for $\mathrm{C}_{28} \mathrm{H}_{28} \mathrm{Zn}_{2} \mathrm{~N}_{2} \mathrm{O}_{14}$ (747.31): C, 45.00; H, 3.78; N, 3.75. Found: C, 44.89; H, 3.65; N, 3.68\%. IR data $(\mathrm{KBr}$, $\mathrm{cm}^{-1}$ ): 3361s, 3067m, 1606s, 1588s, 1550s, 1426s, 1388s, $1362 \mathrm{~m}, 1294 \mathrm{w}, 1161 \mathrm{w}, 1016 \mathrm{w}, 987 \mathrm{~m}, 878 \mathrm{~m}, 831 \mathrm{~m}, 788 \mathrm{~m}$, $707 \mathrm{~m}, 556 \mathrm{~m}, 460 \mathrm{~m}, 425 \mathrm{w}$.

\subsection{3. $\left\{\mathrm{Co}_{2}(\mathrm{bptc})(\mathrm{bpe})\left(\mathrm{H}_{2} \mathrm{O}\right)_{8}\right\}_{n}(3)$}

Complex $\mathbf{3}$ was synthesized in an analogous manner to $\mathbf{2}$ except that $\mathrm{Co}(\mathrm{OAc})_{2} \cdot 4 \mathrm{H}_{2} \mathrm{O}(125 \mathrm{mg}, 0.5 \mathrm{mmol})$ was used instead of $\mathrm{Zn}(\mathrm{OAc})_{2} \cdot 2 \mathrm{H}_{2} \mathrm{O}$. The reaction mixture was cooled, which led to the formation of pink crystals of complex 3. Yield: 53\%. Anal. Calc. for $\mathrm{C}_{28} \mathrm{H}_{32} \mathrm{Co}_{2} \mathrm{~N}_{2} \mathrm{O}_{16}$ (770.42): C 43.65, H 4.19, N 3.64; found C 43.60, H 4.08, $\mathrm{N} 3.57 \%$. IR data $\left(\mathrm{KBr}, \mathrm{cm}^{-1}\right): 3442 \mathrm{~s}, 3285 \mathrm{~s}, 1610 \mathrm{~s}$, $1584 \mathrm{~m}, 1556 \mathrm{~s}, 1403 \mathrm{~s}, 1155 \mathrm{w}, 1018 \mathrm{w}, 979 \mathrm{~m}, 900 \mathrm{w}, 858 \mathrm{w}$, $829 \mathrm{~m}, 795 \mathrm{~m}, 697 \mathrm{~m}, 666 \mathrm{~m}, 584 \mathrm{~m}, 504 \mathrm{w}, 442 \mathrm{w}$.

\subsection{Crystallographic data collection and structure determination}

Single-crystal X-ray diffraction of complexes $\mathbf{1}, \mathbf{2}$ and $\mathbf{3}$ were performed on a BRUKER SMART 1000 CCD diffractometer equipped with a graphite crystal monochromator situated in the incident beam for data collection. Crystallographic data were collected with $\mathrm{Mo} \mathrm{K}_{\alpha}$ radiation $(\lambda=0.71073 \AA$ Á) for three complexes at $296(2) \mathrm{K}$. The structures were solved by direct methods and refined by fullmatrix least squares method on $F^{2}$ values using SHELXL 97 and SHELXL 97 programs, respectively, [8,9]. All non-hydrogen atoms were refined anisotropically. Crystal data, data collection and refinement parameters for three complexes are shown in Table 1, and selected bond lengths and bond angles are listed in Table 2 .

\section{Results and discussion}

\subsection{Syntheses}

The attempt to get crystals suitable for X-ray diffraction from the reaction in solution failed, and insoluble precipi- 
Table 1

Crystallographic data and structure refinement details for complexes 1, 2 and 3

\begin{tabular}{|c|c|c|c|}
\hline Complex & 1 & 2 & 3 \\
\hline Empirical formula & $\mathrm{C}_{46} \mathrm{H}_{36} \mathrm{Cu}_{2} \mathrm{~N}_{10} \mathrm{O}_{12}$ & $\mathrm{C}_{28} \mathrm{H}_{28} \mathrm{Zn}_{2} \mathrm{~N}_{2} \mathrm{O}_{14}$ & $\mathrm{C}_{28} \mathrm{H}_{32} \mathrm{Co}_{2} \mathrm{~N}_{2} \mathrm{O}_{16}$ \\
\hline Formula weight & 1047.93 & 747.31 & 770.42 \\
\hline Crystal system & Monoclinic & Triclinic & Triclinic \\
\hline Space group & $P 2_{1} / c$ & $P \overline{1}$ & $P \overline{1}$ \\
\hline Crystal size $/ \mathrm{mm}^{3}$ & $0.23 \times 0.14 \times 0.07$ & $0.20 \times 0.14 \times 0.08$ & $0.34 \times 0.29 \times 0.09$ \\
\hline$a / \AA ̊$ & $12.6966(2)$ & $7.5977(1)$ & $7.5486(8)$ \\
\hline$b / \AA$ & $12.5949(2)$ & $8.0802(1)$ & $8.9123(9)$ \\
\hline$c / \AA$ & $14.7153(2)$ & $12.1478(2)$ & $23.177(2)$ \\
\hline$\alpha /^{\circ}$ & $90.00(1)$ & $107.793(2)$ & $99.3150(1)$ \\
\hline$\beta /{ }^{\circ}$ & $95.445(2)$ & $93.448(2)$ & $93.509(2)$ \\
\hline$\gamma /{ }^{\circ}$ & $90.00(1)$ & $97.462(2)$ & $91.944(2)$ \\
\hline$V / \AA^{3}$ & $2328.9(5)$ & $700.13(2)$ & $1534.3(3)$ \\
\hline$Z$ & 4 & 2 & 2 \\
\hline$T / \mathrm{K}$ & $296(2)$ & $296(2)$ & $296(2)$ \\
\hline$d_{\text {calc. }} / \mathrm{g} \mathrm{cm}^{-3}$ & 1.500 & 1.772 & 1.668 \\
\hline$\mu / \mathrm{mm}^{-1}$ & 0.988 & 1.793 & 1.163 \\
\hline$F(000)$ & 1080 & 382 & 425 \\
\hline \multirow[t]{3}{*}{ Limiting indices } & $-7 \leqslant h \leqslant 15$ & $-7 \leqslant h \leqslant 9$ & $-7 \leqslant h \leqslant 9$ \\
\hline & $-15 \leqslant k \leqslant 15$ & $-7 \leqslant k \leqslant 9$ & $-10 \leqslant k \leqslant 10$ \\
\hline & $-13 \leqslant l \leqslant 13$ & $-13 \leqslant l \leqslant 14$ & $-23 \leqslant l \leqslant 27$ \\
\hline$\lambda / \AA$ & 0.71073 & 0.71073 & 0.71073 \\
\hline$\theta$ Range $\left({ }^{\circ}\right)$ & $1.62-25.10$ & $1.77-25.10$ & $2.32-25.10$ \\
\hline Reflections collected & 11,560 & 3555 & 7801 \\
\hline Goodness-of-fit on $F^{2}$ & 1.073 & 1.069 & 1.025 \\
\hline$R_{1}^{\mathrm{a}}, w R_{2}^{\mathrm{b}}[I>2 \sigma(I)]$ & $0.0676,0.1647$ & $0.0546,0.1324$ & $0.0472,0.0904$ \\
\hline$R_{1}^{\mathrm{a}}, w R_{2}^{\mathrm{b}}$ [all data] & $0.1367,0.2026$ & $0.0753,0.1483$ & $0.0827,0.1099$ \\
\hline Residuals $\left(\mathrm{e} \AA^{-3}\right)$ & $0.871 /-0.440$ & $0.674 /-0.632$ & $0.495 /-0.473$ \\
\hline
\end{tabular}

${ }^{\mathrm{a}} R_{1}=\Sigma|| F_{\mathrm{o}}|-| F_{\mathrm{c}}|/ \Sigma| F_{\mathrm{o}} \mid$.

b $w R_{2}=\left[\Sigma w\left(F_{\mathrm{o}}^{2}-F_{\mathrm{c}}^{2}\right)^{2} / \Sigma w\left(F_{\mathrm{o}}^{2}\right)^{2}\right]^{1 / 2}$.

Table 2

Selected bond lengths $(\AA)$ and angles $\left({ }^{\circ}\right)$ of complexes 1, 2 and $\mathbf{3}$

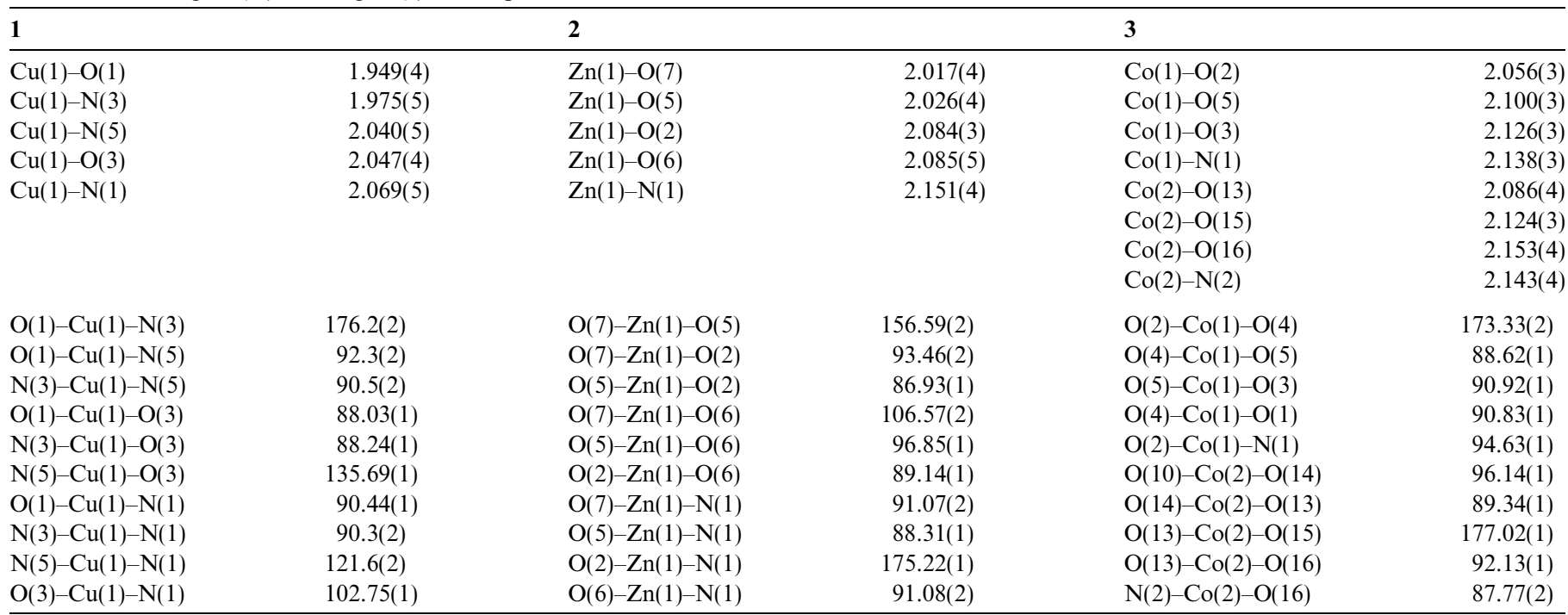

tates were obtained owing to rapid polymerization. Although some crystals were obtained by slowly mixing the reactants via the diffusion method, the crystal quality was not satisfactory. Hence, the hydrothermal reaction method, which is accessible to some metastable complexes and promotes crystal growth, was used in our work. By plenty of parallel experiments, it was found that the $\mathrm{pH}$ values play a crucial role in the reactions, as is the case for some other transition metal coordination polymers reported $[3 b, 10]$. The three complexes were prepared at different $\mathrm{pH}$ : complex $\mathbf{1}$ at $\mathrm{pH}$ 6, complexes $\mathbf{2}$ and $\mathbf{3}$ at $\mathrm{pH}$ 7. If the $\mathrm{pH}$ values of the reactions were lower or higher than the experimental $\mathrm{pH}$ values, no products could be obtained. However, we found that the reactions were not 
sensitive to the reaction temperature. If the reaction temperature was set $10^{\circ} \mathrm{C}$ above or below $145^{\circ} \mathrm{C}$, the ideal crystals still to be obtained.

\subsection{Description of the crystal structures}

\subsection{1. $\left[\mathrm{Cu}_{2}(\right.$ bptc $\left.)(\text { bpdap })_{2}\right] \cdot 4 \mathrm{H}_{2} \mathrm{O}(\mathbf{1})$}

A single-crystal X-ray structural analysis showed that complex 1 crystallizes in monoclinic space group $P 2_{1} / c$. Each copper atom has a slightly distorted $\left[\mathrm{CuN}_{3} \mathrm{O}_{2}\right]$ trigonal bipyramid geometry (Fig. 1). The $\mathrm{Cu}^{\mathrm{II}}$ ion is coordinated to three nitrogen atoms from one bpdap ligand and two oxygen atoms of two different carboxylic groups from one bptc anion. The three pyridyl groups of the bpdap ligand are twisted with the dihedral angle between each pair of neighboring pyridyl rings of $24.16^{\circ}$ and $16.86^{\circ}$, which are larger than that in complex $\{[\mathrm{Co}(\mathrm{bpdc})$ (bpdap) $\left.] \cdot 1.5 \mathrm{H}_{2} \mathrm{O}\right\}_{n}[3 \mathrm{c}]$. The dihedral angle between two benzene rings of bptc is almost $0^{\circ}$, indicating no torsion, which is different from bptc complexes reported $[3 b, 6]$, and the carboxylic groups are not coplanar $\left(47.50^{\circ}\right.$, $72.56^{\circ}$ ) with their connected benzene rings. Complex $\mathbf{1}$ is a perfect molecular architecture based on bptc ligand, the four carboxylic groups of which are all taken coordination by monodenate mode.

It is worth to be noted that the use of $\mathrm{H}$-bonds as a steering force on the control of molecular self-assembly is becoming a very important strategy in chemical and biological systems [11]. Here, the binuclear molecules of complex 1 recognize each other to self-assemble 2-D grid network parallel to the $(0,0,1)$ plane via $\mathrm{H}$-bonded interactions between uncoordinated carboxylic oxygen atoms of the bptc ligand and the amido nitrogen atoms from bpdap ligand $\quad[\mathrm{N}(2) \cdots \mathrm{O}(2)=2.936 \AA, \quad \mathrm{N}(2)-\mathrm{H}(2 \mathrm{C}) \cdots \mathrm{O}(2)=$ $141^{\circ}$, Table S1, see Supporting Information], and the type of $\mathrm{H}$-bonded patterns notated as head-to-tail $\mathrm{R}_{4}{ }^{4}(48)$ are observed in this 2-D array [12], as depicted in Fig. 2a. This type of 2-D network is referred to a typical example of the

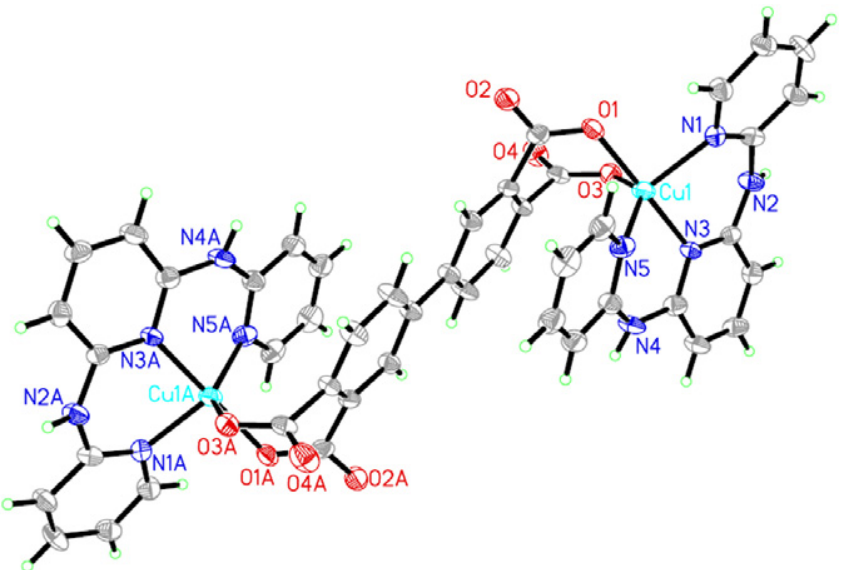

Fig. 1. OPTER representation (30\% thermal probability ellipsoids) of the crystal structure of complex $\mathbf{1}$. The free waters have been omitted for clarity.
$(6,3)$ net in topology [13], triggered by H-bonded interlock (Fig. 2b). A careful examination of the structure indicates that two kinds of chiral H-bonded helices (One is left handed and the other neighboring is right handed), which are composed by $\mathrm{Cu}^{\mathrm{II}}$ ions, carboxylic groups of bptc and bpdap ligands, alternately arrange in the 2-D layer when viewd $[0,0,1]$ direction (Fig. 3), which lead the layers into a wavelike structures. The winding axis of the chains corresponds to the $[0,1,0]$ direction, and the pitch to the length of the chains is with the distance of $12.60 \AA$. We found that the reported examples that have two kinds of helical chains are mainly constructed by covalent bonds of metal ions and ligands [14], but these with two kinds of H-bonded helical chains are scarcely studied up to date $[2 \mathrm{~b}, 6 \mathrm{e}, 15]$. Apparently, the strong hydrogen-bonded interactions undoubtedly steer the rotated direction of the helical chains [16]. To the best of our knowledge, complex 1 represents another new example of metal-bptc complexes containing $\mathrm{H}$-bonded helices since we have reported the first one [6e], and complex 1 obviously superinduces a new member into the family of $\mathrm{H}$-bonded helical chains.

Finally, complex 1 condenses into an extended 3-D network with 1-D open channels by $\mathrm{C}-\mathrm{H} \cdots \Omega[\mathrm{H}(2) \cdots \Omega=$ $\left.3.380 \AA, \mathrm{C}(2)-\mathrm{H}(2) \cdots \Omega=120^{\circ}\right]$ and H-bonded interac-
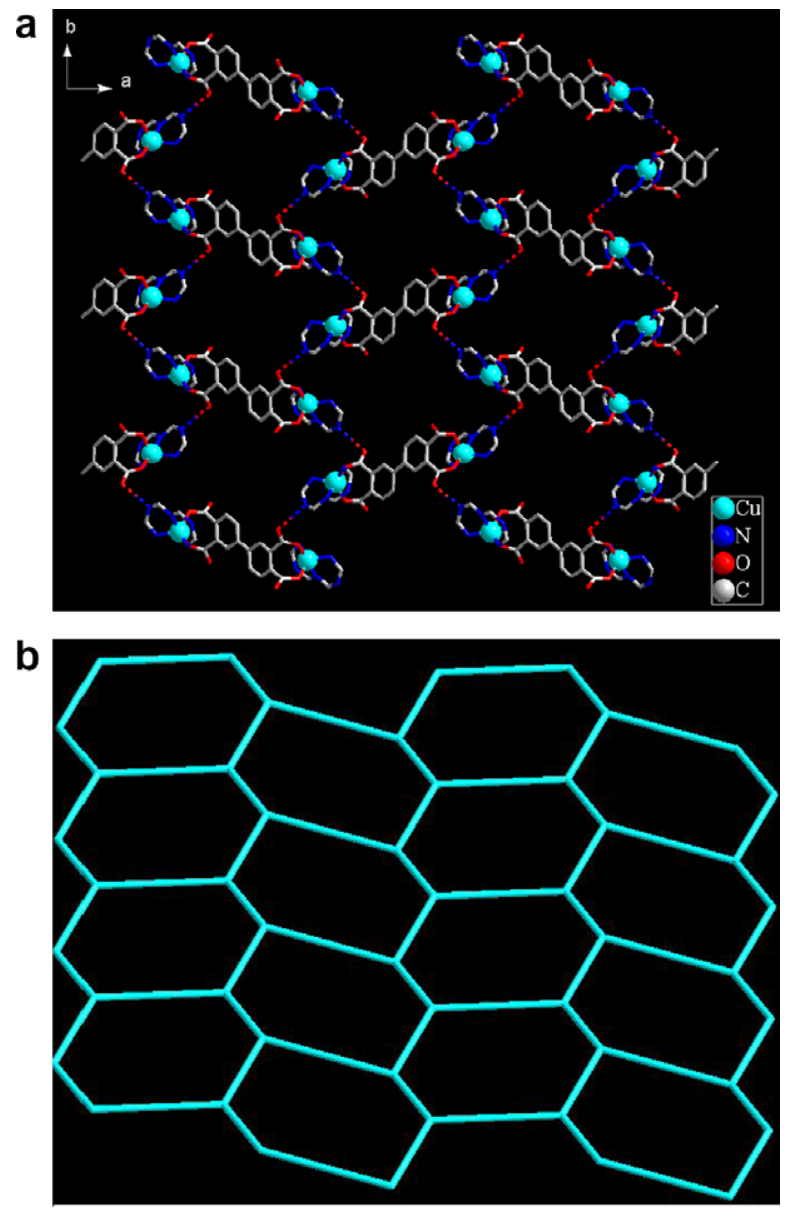

Fig. 2. (a) 2-D supramolecular wavelike network extended by H-bonds along $[0,0,1]$ direction; the dashed-lines stand for H-bonds; (b) the $(6,3)$ topological net in the 2-D layer. Unnecessary atoms are deleted for clarity. 
a

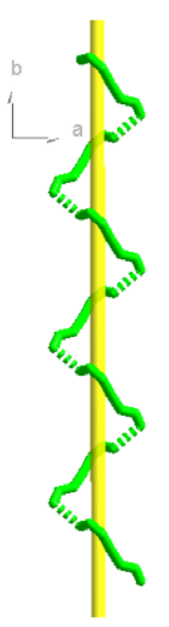

$\mathbf{L}$

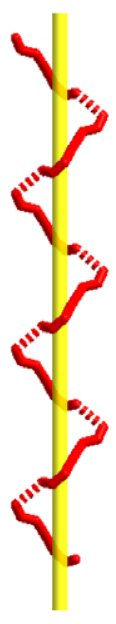

$\mathbf{R}$ b

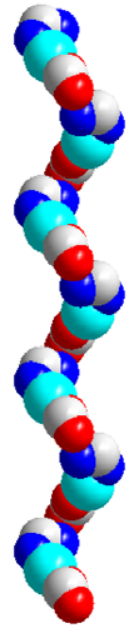

L

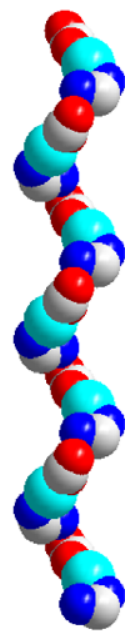

$\mathbf{R}$

Fig. 3. The chiral H-bonded helices in complex 1: (a) The perspective views of the helices; the H-bonds are indicated by dotted lines. (b) The space-filling views of the helical chains (L, left-handed; $\mathrm{R}$, right-handed). Unnecessary atoms are deleted for clarity.

tions $\left[\mathrm{N}(4) \cdots \mathrm{O}(4)=2.892 \AA, \mathrm{N}(4)-\mathrm{H}(4 \mathrm{C}) \cdots \mathrm{O}(4)=168^{\circ}\right]$ when viewed along $[0,1,0]$ direction, as illustrated in Fig. 4. The approximate dimensions of these channels are $16.13 \times 16.00 \AA$ (calculated from the distance of neighboring $\mathrm{Cu}^{I I}$ atoms), where the disordered guest water molecules are located. And the effective potential void volume (ca. $496.2 \AA^{3}$ ) of complex 1 that may be generated after removal of the guest water molecules is $21.3 \%$ of the total volume (ca. $2328.9 \AA^{3}$ ) as estimated by PLATON program [17], which means that it may be able to incorporate some guest small molecules.

\subsection{2. $\left\{\mathrm{Zn}_{2}(\mathrm{bptc})(\mathrm{bpe})\left(\mathrm{H}_{2} \mathrm{O}\right)_{6}\right\}_{n}$ (2)}

A single X-ray analysis revealed that complex 2 possesses a 1-D neutral chain constructed from alternating

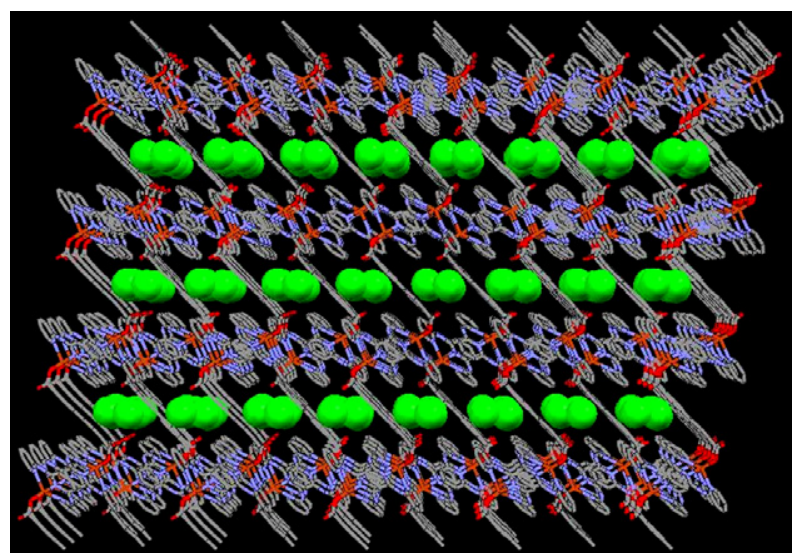

Fig. 4. View of 3-D network of 1 containing 1-D open channels filling guest water molecules. The green balls stand for water molecules. (For interpretation of the references to color in this figure legend, the reader is referred to the web version of this article.)

bptc and bpe ligands, as shown in Fig. 5. It is very interesting that the bptc ligands adopt a bis(monodentate) bridging mode $\left(4,4^{\prime}\right.$-carboxylic groups) in this case, and other two carboxylic groups are also deprotonated but uncoordinated with metal ions. The local coordination environment around the zinc(II) shows that the zinc sits on a center of asymmetry, and each five-coordinated zinc center is in a distorted trigonal bipyramid geometry. The $\mathrm{Zn}-\mathrm{N}$ bond length is $2.151 \AA$ and the $\mathrm{Zn}-\mathrm{O}$ bond lengths are in the range $2.017-2.085 \AA$, which are all within the normal ranges [6a,18].

Complex 2 is a isostructural to a $\mathrm{Cu}$ (II) complex that we have reported recently [6e], but we found, simultaneously, that another 2-D $\mathrm{Zn}(\mathrm{II})$ complex $\left\{\mathrm{Zn}\left(\mathrm{H}_{2} \text { bptc }\right)(\mathrm{bpe})\right\}_{n}$ constructed from $\mathrm{H}_{4}$ bptc and the same auxiliary ligand bpe in different conditions (hydrothermally reaction temperature $T=160{ }^{\circ} \mathrm{C}$ and $\mathrm{pH} 5$ ) has been reported lately [6d]. In the complex, $\mathrm{H}_{4}$ bptc ligand was partially deprotonated (3,3'-carboxylic groups) and adopted two different coordinated fashions ( $\mu_{2}$-bridging and chelated modes) with different ions. Compared complex $\mathbf{2}$ with complex $\left\{\mathrm{Zn}\left(\mathrm{H}_{2} \text { bptc }\right)(\mathrm{bpe})\right\}_{n}$, the results indicated that the different reaction temperature, $\mathrm{pH}$ value, and stoichiometry would induce absolutely different architectures even if utilized the same starting reaction materials.

Zinc atoms have a weak equatorial connection to semicoordinated water centro-symmetrically related molecules $[\mathrm{Zn}(1) \cdots \mathrm{O}(7)=2.705(4) \AA$, symmetry code: $1-x, 1-y$, $1-z]$ resulting in a $5+1$ coordination sphere (Fig. 6a). The 2-D supramolecular layers are generated via joining adjacent 1-D chains each other by $\mathrm{H}$-bonded interactions and semi-coordination mentioned above. We found that the structure is mainly dominated by two different types of H-bonds (Fig. 6b) [12]. Of them, two interactions viz. $[\mathrm{O}(5)-\mathrm{H}(5 \mathrm{~B}) \cdots \mathrm{O}(4), \mathrm{O}(6)-\mathrm{H}(6 \mathrm{~B}) \cdots \mathrm{O}(3)]$ together constitute a 8 -membered $\mathrm{H}$-bonded rings [graph set $\mathrm{R}_{2}{ }^{2}(8)$ ]. Another type of $\mathrm{H}$-bonded interaction is characterized by the formation of a similar 12-membered rings [graph set $\left.\mathrm{R}_{2}{ }^{2}(12)\right]$ comprised of the interactions $[\mathrm{O}(7)-\mathrm{H}(7 \mathrm{~B}) \cdots$ $\mathrm{O}(1)]$. Then these no interpenetrated layers are interlinked with an ABAB sequence [6c,19] to form the 3-D supramolecular framework by H-bonded self-assembly $[\mathrm{O}(6)$ $\mathrm{H}(6 \mathrm{~B}) \cdots \mathrm{O}(2), \mathrm{O}(7)-\mathrm{H}(7 \mathrm{C}) \cdots \mathrm{O}(4)]$ with 1-D channels, where no guest molecules exist (Fig. 7).

\subsection{3. $\left\{\mathrm{Co}_{2}(\mathrm{bptc})(\mathrm{bpe})\left(\mathrm{H}_{2} \mathrm{O}\right)_{8}\right\}_{n}(3)$}

The crystal structure of complex 3 also contains a neutral 1-D chain based on bptc and bpe ligands. The two kinds of cobalt atoms are all $4+2$ six-coordinated in a slightly distorted octahedral coordination environment with four water molecules located in the equatorial plane, one nitrogen atom from bpe ligand and one oxygen atom from bptc taken on the apical positions (Fig. 8), the bond lengths of which are all within the normal ranges that have been reported in the literatures $[13 \mathrm{e}, 20]$. The two sorts of best equatorial planes are all defined by coordinated water molecules; they are with the dihedral angle of $10.14^{\circ}$. 


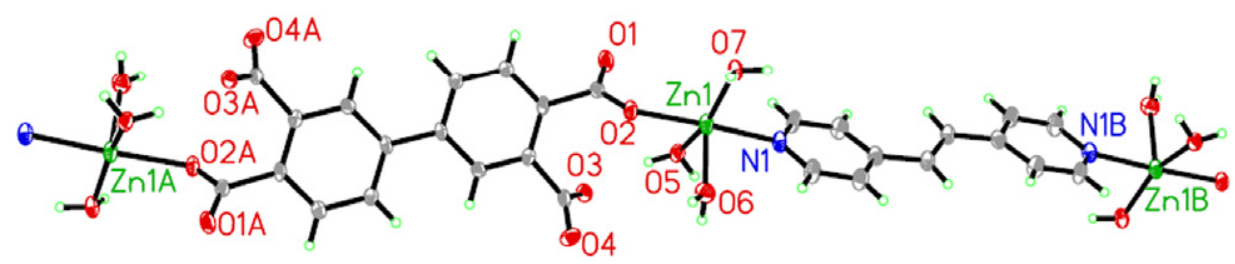

Fig. 5. The repeated unit of the infinite coordination polymer of complex 2.

a

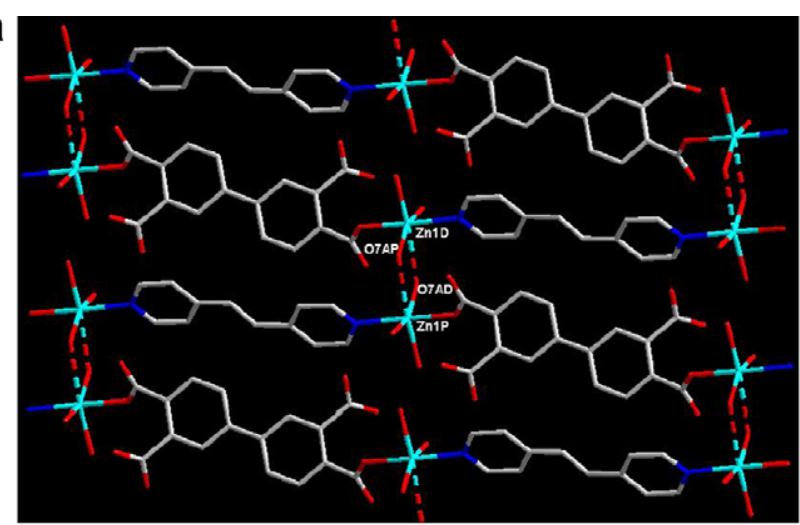

b

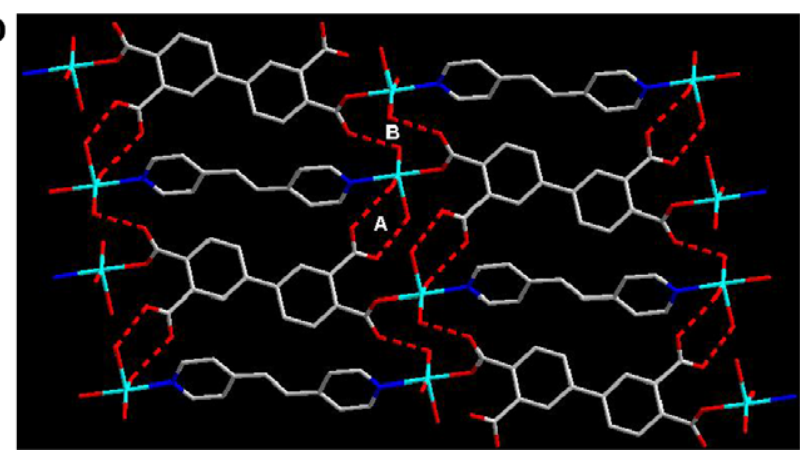

Fig. 6. The 2-D layer based on semi-coordination and H-bonds: (a) $\mathrm{Zn}$... O semi-coordination. (b) H-bonded patterns in the layer (A and $\mathbf{B}$ ).
In the complex, the four carboxylic groups of bptc ligands are deprotonated, but one of the most intriguing features is that bptc ligands are taken on coordination with the oxygen atoms of 3,4'-carboxylic groups, which is different from complexes $\mathbf{1}$ and $\mathbf{2}$; bptc and bpe ligands are distorted in the complex with the dihedral angles of $17.70^{\circ}$ and $6.09^{\circ}$ between the planes of the phenyl rings, respectively. Compared with the complexes $\mathbf{2}$ and $\mathbf{3}$, we realized that the different metal ions play a crucial role on synthesizing the polymers when utilized the same ligands, resulting in different coordination fashions of the ligands.

Because of possessing multi-uncoordinated carboxylic oxygen atoms and coordinated water molecules in the complex, plenty of $\mathrm{H}$-bonds ensure the higher dimensional framework to be constructed. We found that four types of $\mathrm{H}$-bonded patterns $\mathrm{A}-\mathrm{D}$ [12], notated as $\mathrm{R}_{2}{ }^{1}(6)$ $[\mathrm{O}(13)-\mathrm{H}(13 \mathrm{C}) \cdots \mathrm{O}(9), \quad \mathrm{O}(14)-\mathrm{H}(14 \mathrm{~B}) \cdots \mathrm{O}(9)], \quad \mathrm{R}_{2}^{2}(8)$ $[\mathrm{O}(4)-\mathrm{H}(4 \mathrm{C}) \cdots \mathrm{O}(3)], \mathrm{R}_{2}{ }^{2}(8)[\mathrm{O}(1)-\mathrm{H}(1 \mathrm{~B}) \cdots \mathrm{O}(7), \mathrm{O}(2)-$ $\mathrm{H}(2 \mathrm{~B}) \cdots \mathrm{O}(8)]$ and $\mathrm{R}_{2}{ }^{2}(8) \quad[\mathrm{O}(15)-\mathrm{H}(15 \mathrm{C}) \cdots \mathrm{O}(11)$, $\mathrm{O}(16)-\mathrm{H}(16 \mathrm{C}) \cdots \mathrm{O}(12)]$ are obtained in the 2-D framework, as depicted Fig. 9. Just like complex 2, these resultant 2-D layers are further extended into a 3-D supramolecular network (Fig. S1, see Supporting Information) via $\mathrm{H}$ bonded interlocks $[\mathrm{O}(1)-\mathrm{H}(1 \mathrm{C}) \cdots \mathrm{O}(4), \mathrm{O}(3)-\mathrm{H}(3 \mathrm{C}) \cdots$ $\mathrm{O}(8), \mathrm{O}(14)-\mathrm{H}(14 \mathrm{C}) \cdots \mathrm{O}(12), \mathrm{O}(13)-\mathrm{H}(13 \mathrm{~B}) \cdots \mathrm{O}(16)]$.

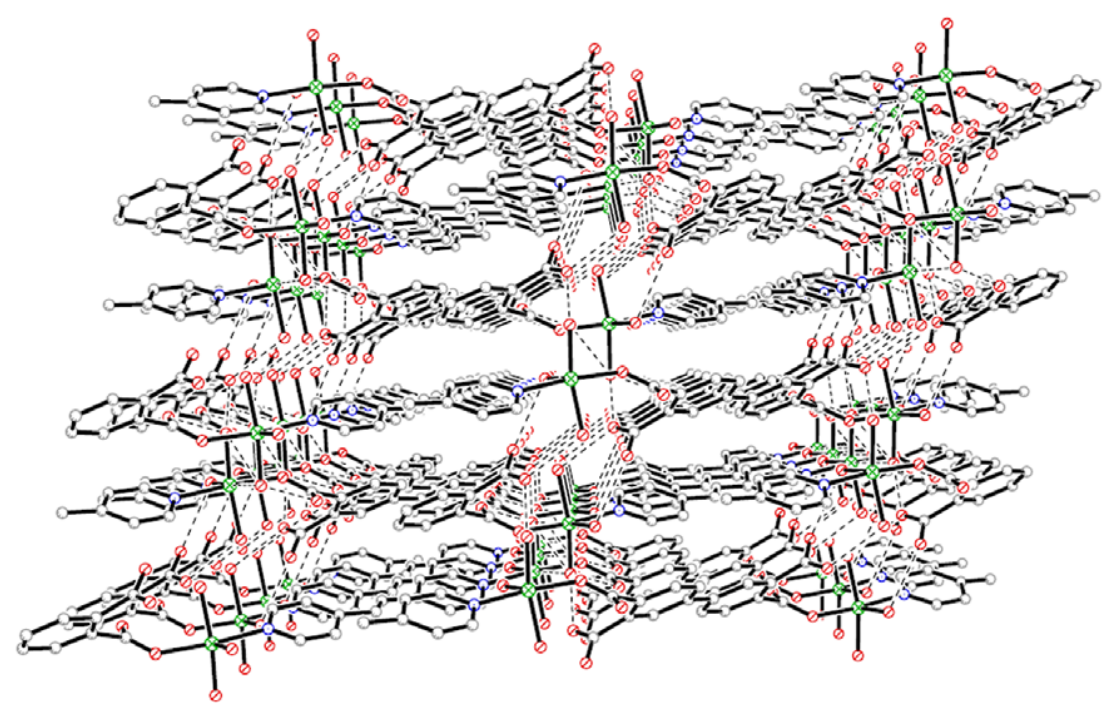

Fig. 7. The 3-D supramolecular framework of complex 2 with 1-D channels. 


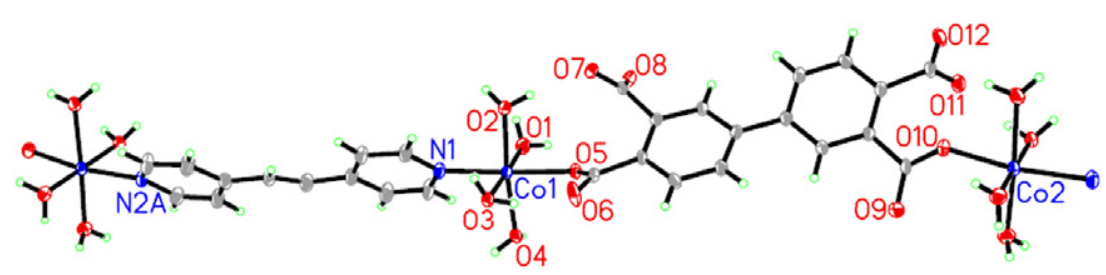

Fig. 8. Perspective view of the coordination environment of the cobalt atom in complex 3 .

\subsection{Spectroscopic properties}

The IR spectrums of three complexes were performed as $\mathrm{KBr}$ pellets in the range of $4000-400 \mathrm{~cm}^{-1}$ (Fig. S2, see Supporting Information). The three complexes show the characteristic bands of the carboxylic groups in the usual region [21] at $1680-1550 \mathrm{~cm}^{-1}$ for the asymmetric vibration and at $1420-1330 \mathrm{~cm}^{-1}$ for the symmetric, and the value $\Delta\left[v_{\text {as }}\right.$ $\left.\left(\mathrm{COO}^{-}\right)-v_{\mathrm{s}}\left(\mathrm{COO}^{-}\right)\right]>200 \mathrm{~cm}^{-1}$ for three complexes reveals that the carboxylic groups are coordinated in a monodentate mode [22], which are consistent with the results of the X-ray analysis. As well as bands of the bpdap at $1582 \mathrm{~cm}^{-1}$, $1545 \mathrm{~cm}^{-1}, 1489 \mathrm{~cm}^{-1}$ for 1 , the bands of the bpe ligand at $1550 \mathrm{~cm}^{-1}$ for 2 and $1584 \mathrm{~cm}^{-1}, 1556 \mathrm{~cm}^{-1}$ for 3 , respectively. These proposals are in agreement with the crystal structures. Less significant absorption bands occur at $\sim 3060-2930 \mathrm{~cm}^{-1}$ (stretching vibrations of the aromatic C-H groups), $\sim 860-720 \mathrm{~cm}^{-1}$ (out-of-plane motion of the $\mathrm{C}-\mathrm{H}$ groups of the pyridyl rings) and $\sim 630 \mathrm{~cm}^{-1}\left[v_{(\mathrm{M}-\mathrm{N})}\right.$ vibration] [23].

Taking the excellent luminescent properties of polynuclear $d^{10}$ metal complexes into account, the luminescence of complex 2 and free bptc ligand were investigated at room temperature. Complex 2 exhibits fluorescent emission maximum at $\lambda=448 \mathrm{~nm}$ but bptc at $\lambda=402 \mathrm{~nm}$ upon excitation at $\lambda=310 \mathrm{~nm}$ (Fig. 10), no enhancement in the fluorescence intensity is realized compared with the free ligand. Since it was found that the free bpe ligand does not show any luminescence in the range $400-800 \mathrm{~nm}$ at the room temperature, the peak may be interpreted as a ligand-to-

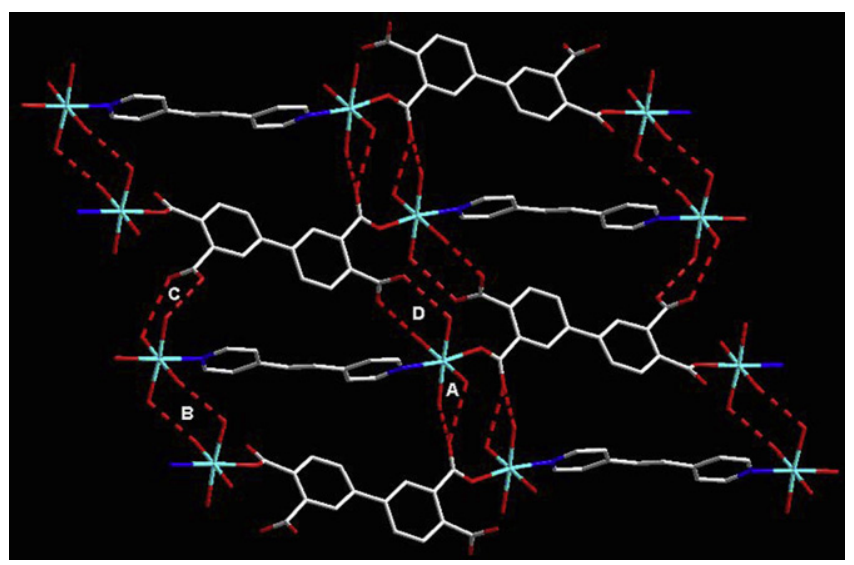

Fig. 9. The 2-D supramolecular network of complex 3 constructed from four H-bonded patterns (A, B and C). The broken lines represent H-bonded interactions.

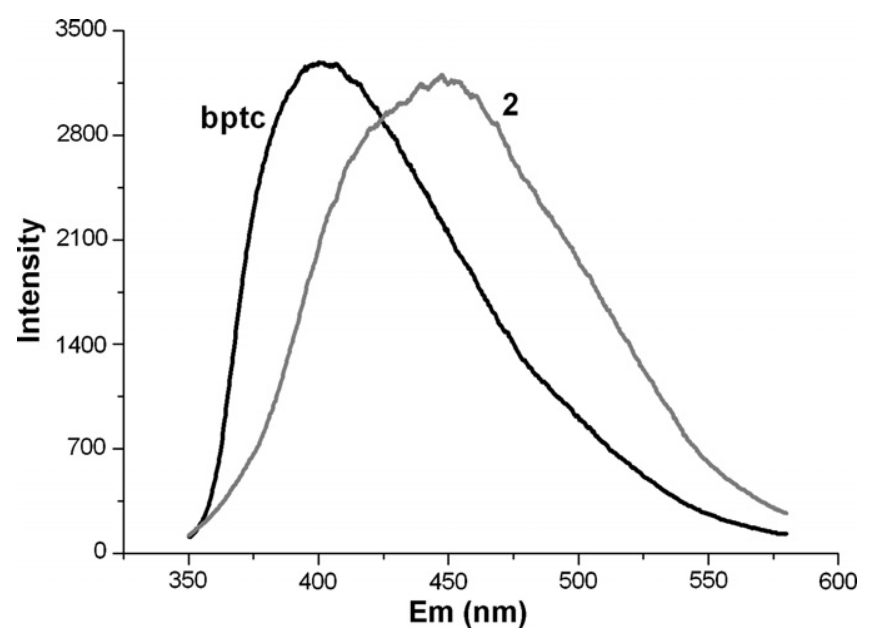

Fig. 10. Photoluminescent spectra of bptc ligand and complex 2 in the solid state at room temperature. $\lambda_{\mathrm{Ex}}=310 \mathrm{~nm}, \lambda(\mathrm{bptc})_{\mathrm{Em}}=402 \mathrm{~nm}$, $\lambda(2)_{\mathrm{Em}}=448 \mathrm{~nm}$.

metal charge transfer (LMCT) [24]. This observation indicates that complex 2 may be an excellent candidate for potential photoactive materials.

\subsection{Thermal gravimetric analyses}

Thermal gravimetric analyses (TGA) for complexes $\mathbf{1 , 2}$ and $\mathbf{3}$ were recorded under a nitrogen atmosphere between 50-800 ${ }^{\circ} \mathrm{C}$ (Fig. S3, see Supporting Information). For complex 1, TGA result shows the initial weight loss of $7.47 \%$ at $\sim 65-124{ }^{\circ} \mathrm{C}$, corresponding to the removal of four water molecules per formula unit (calc. 6.86\%). When the temperature holds on rising, the products lose the bptc and bpdap ligands, finally the remaining weight of $13.33 \%$ corresponds to the percentage (calc. $13.60 \%$ ) of $\mathrm{Cu}$ and $\mathrm{O}$ components, indicating that the final product is $\mathrm{Cu}_{2} \mathrm{O}$. The TGA traces of $\mathbf{2}$ and $\mathbf{3}$ are much like that observed for $\mathbf{1}$ : complex 2 loses six waters at $67-300{ }^{\circ} \mathrm{C}$ (observed $13.48 \%$, calc. $14.46 \%$ ) and complex 3 loses eight water molecules at $76-260{ }^{\circ} \mathrm{C}$ (observed $18.32 \%$, calc. $18.71 \%$ ) respectively. And the remaining weight of $21.99 \%$ (calc. $21.78 \%$ ) for 2 (observed $19.21 \%$, calc. $19.45 \%$ for 3) indicates that the final product is $\mathrm{ZnO}(\mathrm{CoO})$.

\subsection{X-ray powder diffraction measurement}

To confirm whether the analyzed crystal structures are truly representative of the bulk materials X-ray powder 


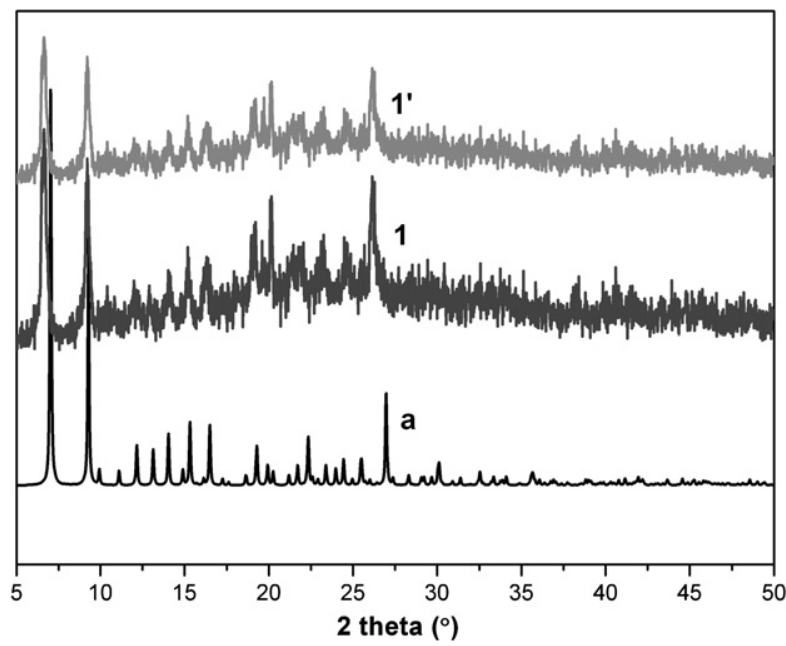

Fig. 11. XRPD patterns for complex 1: (a) calculated patterns from single-crystal X-ray data; $(\mathbf{1})$ taken at room temperature; $\left(\mathbf{1}^{\prime}\right)$ after heating at $94{ }^{\circ} \mathrm{C}$ for $2 \mathrm{~h}$.

diffraction (XRPD) experiments were carried out for complexes $\mathbf{1}, \mathbf{2}$ and $\mathbf{3}$ at room temperature (Fig. S4, see Supporting Information). Although the experimental patterns have a few unindexed diffraction peaks and some are slightly broadened in comparison with those simulated from the single-crystal modes, it still can be considered that the bulk synthesized materials and the as-grown crystals for complexes 1, $\mathbf{2}$ and $\mathbf{3}$ are homogeneous.

In addition, to confirm the stable framework of complex 1, the original sample and dehydrated sample were characterized by XRPD at the room temperature (Fig. 11). For complex 1 after heating a sample at $94{ }^{\circ} \mathrm{C}$ for $2 \mathrm{~h}$, the disordered guest water molecules are removed (the evacuated frameworks are defined as $\mathbf{1}^{\prime}$ ) [25]. According to the results of the experiment, we found that the XRPD pattern of $\mathbf{1}^{\prime}$ is very similar to complex $\mathbf{1}$, although some minor differences can be seen in the positions, intensities and widths of some peaks, indicating that the framework of complex 1 is retained after the removal of the guest species. On the other hand, it may also indicate that the 1-D open channels in complex 1 have the ability to absorb other hydrophilic small molecules. An investigation of these properties and the synthesis of other metal-bptc frameworks are underway.

\section{Conclusion}

In summary, we have successfully synthesized three complexes constructed from bptc ligand in the presence of N-containing auxiliary ligands (bpdap, bpe) at different $\mathrm{pH}$ values. Importantly, $\mathrm{H}$-bonded interactions have an important influence in linking the low-dimensional entities into high-dimensional supramolecular framework in this system and the different coordination modes of bptc may have a significant effect on the formation of the resulting structures. More significantly, it has been found that two kinds of chiral H-bonded helices and 1-D open channels exist in complex 1, and the free disorder water molecules are located in these 1-D channels. Additionally, complex 2 shows excellently luminescent.

\section{Acknowledgments}

This work was supported by the National Natural Science Foundation of China (No. 20771090) and TRAPOYT, and Specialized Research Found for the Doctoral Program of Higher Education (No. 20050697005).

\section{Appendix A. Supplementary data}

Crystallographic data for the structural analysis have been deposited with the Cambridge Crystallographic Data Centre, CCDC No. 649617 for 1, 649618 for 2 and 649619 for 3. Copies of this information may be obtained free of charge on application to CCDC, 12 Union Road, Cambridge CB2 1EZ, UK (fax: +44 1223336 033; e-mail: deposit@ccdc.cam.ac.uk or http://www.ccdc.cam.ac.uk). Supplementary data: The coordination modes of the bptc ligand, The table of H-bonded lengths and angles, The TG curves of the three complexes, The XRPD pattern for complexes $\mathbf{2}$ and 3, and additional plots of the structures. Supplementary data associated with this article can be found, in the online version, at doi:10.1016/ j.molstruc.2007.12.033.

\section{References}

[1] (a) I. Boldog, E.B. Rusanov, A.N. Chernega, J. Sieler, K.V. Domasevitch, Angew. Chem. Int. Ed. 40 (2001) 3435;

(b) Y. Wang, J.-H. Yu, Y. Li, S. Zhan, R.-R. Xu, Chem. Eur. J. 9 (2003) 5045;

(c) Y. Song, J.-H. Yu, Y. Li, G.-H. Li, R.-R. Xu, Angew. Chem. Int. Ed. 43 (2004) 2399;

(d) K.V. Domasevitch, I. Boldog, E.B. Rusanov, J. Hunger, S. Blaurock, M. Schröder, J. Sieler, Z. Anorg. Allg. Chem. 631 (2005) 1095.

[2] (a) S.-Q. Zang, Y. Su, C.-Y. Duan, Y.-Zh. Li, H.-Zh. Zhu, Q.-J. Meng, Chem. Comm. (2006) 4997;

(b) D.-R. Xiao, E.-B. Wang, H.-Y. An, Y.-G. Li, L. Xu, Cryst. Growth. Des. 7 (2007) 506.

[3] (a) J. Zhang, Z.-J. Li, Y. Kang, J.-K. Cheng, Y.-G. Yao, Inorg. Chem. 43 (2004) 8085;

(b) X.-L. Wang, C. Chao, E.-B. Wang, Cryst. Growth. Des. 6 (2006) 439 ;

(c) L.-J. Zhou, Y.-Y. Wang, C.-H. Zhou, C.-J. Wang, Q.-Zh. Shi, S.-M. Peng, Cryst. Growth. Des. 7 (2007) 300.

[4] (a) J.L. Atwood, J.E.D. Davies, D.D. MacNicol, F. Vögtle, J.M. Lehn, Comprehensive Supramolecular Chemistry, vol. 9, Pergamon Press, New York, 1996;

(b) T.J. Barton, L.M. Bull, W.G. Klemperer, D.A. Loy, B. McEnaney, M. Misono, P.A. Monson, G. Pez, G.W. Scherer, J.C. Vartuli, O.M. Yaghi, Chem. Mater. 11 (1999) 2633;

(c) C. Janiak, Dalton Trans. (2003) 2781.

[5] (a) W. Mori, F. Inoue, K. Yoshida, H. Nakayama, S. Takamizawa, M. Kishita, Chem. Lett. 12 (1997) 1219;

(b) S.S.-Y. Chui, S.M.-F. Lo, J.P.H. Charmant, A.G. Orpen, I.D. Williams, Science 283 (1999) 1148;

(c) S.M.-F. Lo, S.S.-Y. Chui, L.-Y. Shek, Z.-Y. Lin, X.X. Zhang, G.-H. Wen, I.D. Williams, J. Am. Chem. Soc. 122 (2000) 6293; 
(d) Q. Shi, R. Cao, D.-F. Sun, M.-Ch. Hong, Y.-C. Liang, Polyhedron 20 (2001) 3287;

(e) H.-F. Zhu, J. Fan, T. Okamura, Zh.-H. Zhang, G.-X. Liu, K.-B. Yu, W.-Y. Sun, N. Ueyama, Inorg. Chem. 45 (2006) 3941;

(f) Q.-R. Fang, G.-S. Zhu, M. Xue, J.-Y. Sun, F.-X. Sun, S.-L. Qiu, Inorg. Chem. 45 (2006) 3582;

(g) X.-J. Luan, X.-H. Cai, Y.-Y. Wang, C.-J. Wang, P. Liu, Q.-Z. Shi, S.-M. Peng, Chem. Eur. J. 12 (2006) 6281.

[6] (a) X.-L. Wang, Ch. Qin, E.-B. Wang, L. Xu, Eur. J. Inorg. Chem. (2005) 3418;

(b) X.-R. Hao, Z.-M. Su, Y.-H. Zhao, K.-Z. Shao, Y. Wang, Acta Cryst. C61 (2005) m469;

(c) J.-J. Wang, M.-L. Yang, H.-M. Hu, G.-L. Xue, D.-S. Li, Q.-Z. Shi, Z. Anorg. Allg. Chem. 633 (2007) 341;

(d) J.-J. Wang, L. Gou, H.-M. Hu, Z.-X. Han, D.-S. Li, G.-L. Xue, M.-L. Yang, Q.-Z. Shi, Cryst. Growth. Des. 7 (2007) 1514;

(e) G.-P. Yang, Y.-Y. Wang, L.-F. Ma, J.-Q. Liu, Y.-P. Wu, W.-P. Wu, Q.-Z. Shi, Eur. J. Inorg. Chem. (2007) 3892;

(f) D.-F. Weng, X.-J. Zheng, L.-C. Li, W.-W. Yang, L.-P. Jin, Dalton Trans. (2007) 4822.

[7] S.-J. Shi, C.-C. Chou, G.-H. Lee, C.-C. Wang, S.-M. Peng, Angew. Chem. Int. Ed. 36 (1997) 56.

[8] G.M. Sheldrick, SHELXS, University of Göttingen, Germany, 1997.

[9] G.M. Sheldrick, SHELXL, Program for the Refinement of Crystal Structures, University of Göttingen, Germany, 1997.

[10] (a) J.-C. Dai, X.-T. Wu, Z.-Y. Fu, C.-P. Cui, S.-M. Hu, W.-X. Du, L.-M. Wu, H.-H. Zhang, R.-Q. Sun, Inorg. Chem. 41 (2002) 1391; (b) J.-C. Dai, X.-T. Wu, S.-M. Hu, Z.-Y. Fu, J.-J. Zhang, W.-X. Du, H.-H. Zhang, R.-Q. Sun, Eur. J. Inorg. Chem. (2004) 2096;

(c) X.-P. Li, J.-Y. Zhang, M. Pan, S.-R. Zheng, Y. Liu, C.-Y. Su, Inorg. Chem. 46 (2007) 4617.

[11] Hydrogen bonding control of molecular self-sassembly: recent advances in design, synthesis, and analysis: (a) J.R. Fredericks, A.D. Hamilton, in: J.P. Sauvage, M.W. Hosseini (Eds.), Comprehensive Supramolecular Chemistry, vol. 9, Pergamon, Oxford, 1996, Chapter 16;

(b) M.-L. Tong, X.-M. Chen, S.-W. Ng, Inorg. Chem. Commun. 3 (2000) 436;

(c) M.-L. Tong, S.-L. Zheng, X.-M. Chen, Polyhedron 19 (2000) 1809; (d) J.M. Lehn, Science 295 (2002) 2400;

(e) J. Zhang, Z.-J. Li, Y. Kang, J.-K. Cheng, Y.-G. Yao, Inorg. Chem. 43 (2004) 8085;

(f) S.K. Ghosh, P.K. Bharadwaj, Eur. J. Inorg. Chem. (2005) 4886.

[12] (a) M.C. Etter, Acc. Chem. Res. 23 (1990) 120;

(b) M.C. Etter, J. Phys. Chem. 95 (1991) 4601;

(c) J. Bernstein, R.E. Davis, L. Shimoni, N.L. Chang, Angew. Chem. Int. Ed. Engl. 34 (1995) 1555;

(d) S. Banerjee, A.R. Choudhury, T.N.B. Gow, S. Chaudhuri, A. Ghosh, Polyhedron 26 (2007) 24.

[13] (a) C.-Y. Su, Y.-P. Cai, C.-L. Chen, B.-S. Kang, Inorg. Chem. 40 (2001) 2210;

(b) R.-F. Hu, J. Zhang, Y. Kang, Y.-G. Yao, Inorg. Chem. Commun. 8 (2005) 828;

(c) X.-Q. Lu, J.-J. Jiang, H.-C. Loye, B.-S. Kang, C.-Y. Su, Inorg. Chem. 44 (2005) 1810;

(d) F.-Q. Wang, X.-J. Zheng, Y.-H. Wan, C.-Y. Sun, Z.-M. Wang, K.-Z. Wang, L.-P. Jin, Inorg. Chem. 46 (2007) 2956;

(e) Y.-Y. Liu, J.-F. Ma, J. Yang, Z.-M. Su, Inorg. Chem. 46 (2007) 3027.

[14] (a) C. Piguet, G. Bernardinelli, G. Hopfgartner, Chem. Rev. 97 (1997) 2005;

(b) Y.-P. Cai, H.-X. Zhang, A.-W. Xu, C.-Y. Su, C.-L. Chen, H.-Q. Liu, L. Zhang, B.-S. Kang, J. Chem. Soc. Dalton Trans. (2001) 2429; (c) L. Plasseraud, H. Maid, F. Hampel, R.W. Saalfrank, Chem. Eur.
J. 7 (2001) 4007;

(d) J.-C. Yao, W. Huang, B. Li, S.-H. Gou, Y. Xu, Inorg. Chem. Commun. 5 (2002) 711;

(e) Z.-Q. Qin, M.C. Jennings, R.J. Puddephatt, Chem. Eur. J. 8 (2002) 735;

(f) C.-Y. Su, A.M. Goforth, M.D. Smith, H.-C.Z. Loye, Inorg. Chem. 42 (2003) 5685.

[15] (a) L. Han, M.-C. Hong, R.-H. Wang, J.-H. Luo, Z.-Z. Lin, D.-Q. Yuan, Chem. Commun. (2003) 2580;

(b) Y.-Q. Sun, J. Zhang, Y.-M. Chen, G.-Y. Yang, Angew. Chem. Int. Ed. 44 (2005) 5814;

(c) S. Zang, Y. Su, Y. Li, Z. Ni, H. Zhu, Q. Meng, Inorg. Chem. 45 (2006) 3855 ;

(d) D.-R. Xiao, E.-B. Wang, H.-Y. An, Y.-G. Li, Zh.-M. Su, Ch.-Y. Sun, Chem. Eur. J. 12 (2006) 6528;

(e) Y.-G. Huang, Y.-Q. Gong, F.-L. Jiang, D.-Q. Yuan, M.-Y. Wu, Q. Gao, W. Wei, M.-C. Hong, Cryst. Growth. Des. 7 (2007) 1385.

[16] (a) I. Boldog, E.B. Rusanov, A.N. Chernega, J. Sieler, K.V. Domasevitch, Angew. Chem. Int. Ed. 40 (2001) 3435;

(b) K.V. Domasevitch, I. Boldog, E.B. Rusanov, J. Hunger, S. Blaurock, M. Schröder, J. Sieler, Z. Anorg. Allg. Chem. 631 (2005) 1095.

[17] A.L. Spek, PLATON99, A Multipurpose Crystallographic Tool; Utrecht University, Utrecht, The Netherlands, 1999.

[18] (a) R.-G. Xiong, J.-L. Zuo, X.-Z. You, B.F. Abrahams, Z.-P. Bai, C.-M. Che, H.-K. Fun, Chem. Commun. (2000) 2061;

(b) L.-Y. Zhang, G.-F. Liu, S.-L. Zheng, B.-H. Ye, X.-M. Zhang, X.-M. Chen, Eur. J. Inorg. Chem. (2003) 2965;

(c) X. He, C.-Z. Can, D.-Q. Yuan, L.-J. Chen, Q.-Z. Zhang, C.-D. Wu, Eur. J. Inorg. Chem. (2005) 4598;

(d) X.-L. Wang, C. Qin, E.-B. Wang, L. Xu, Cryst. Growth. Des. 6 (2006) 2061.

[19] Y.-T. Wang, G.-M. Tang, W.-Y. Ma, W.-Z. Wan, Polyhedron 26 (2007) 782

[20] (a) J.-Y. Lu, M.A. Lawandy, J. Li, T. Yuen, C.-L. Lin, Inorg. Chem. 38 (1999) 2695;

(b) Z.-Y. Fu, X.-T. Wu, J.-C. Dai, S.-M. Hu, W.-X. Du, H.-H. Zhang, R.-Q. Sun, Eur. J. Inorg. Chem. (2002) 2730;

(c) Y.-L. Wang, D.-Q. Yuan, W.-H. Bi, X. Li, X.-J. Li, F. Li, R. Cao, Cryst. Growth. Des. 5 (2005) 1849;

(d) L.-M. Duan, F.-T. Xie, X.-Y. Chen, Y. Chen, Y.-K. Lu, P. Cheng, J.-Q. Xu, Cryst. Growth. Des. 6 (2006) 1101;

(e) Y.-L. Lu, J.-Y. Wu, M.-C. Chan, S.-M. Huang, C.-S. Lin, T.-W. Chiu, Y.-H. Liu, Y.-S. Wen, C.-H. Ueng, T.-M. Chin, C.-H. Hung, K.-L. Lu, Inorg. Chem. 45 (2006) 2430.

[21] L.J. Bellamy, The Infrared Spectra of Complex Molecules, John Wiley \& Sons, New York, 1958.

[22] (a) G.B. Deacon, R. Phillips, J. Coord. Chem. Rev. 33 (1980) 227; (b) V. Zeleňák, I. CÍsařová, P. Llewellyn, Inorg. Chem. Commun. 10 (2007) 27.

[23] D.-S. Li, Y.-Y. Wang, X.-J. Luan, P. Liu, C.-H. Zhou, M.-R. Ma, Q.-Z. Shi, Eur. J. Inorg. Chem. (2005) 2678.

[24] (a) A. Meijerink, G. Blasses, M. Blasbeek, J. Phys: Condens. Matter. 2 (1990) 6303;

(b) R. Bertoncello, M. Bettinelli, M. Cassrin, A. Gulino, E. Tondello, A. Bittadini, Inorg. Chem. 31 (1991) 1558;

(c) J. Tao, J.-X. Shi, M.-L. Tong, X.-X. zhang, X.-M. Chen, Inorg. Chem. 40 (2001) 6328.

[25] (a) S. Kitagawa, R. Kitaura, S. Noro, Angew. Chem. Int. Ed. 43 (2004) 2334;

(b) X. Lin, A.J. Blake, C. Wilson, X.Z. Sun, N.R. Champness, M.W. George, P. Hubberstey, R. Mokaya, M. Schröder, J. Am. Chem. Soc. 128 (2006) 10745. 